\section{(6) OPEN ACCESS}

\title{
Multilevel analysis of the determinants of smoking and second-hand smoke exposure in a tobacco-cultivating rural area of southwest China
}

\author{
Le Cai, ${ }^{1}$ Xinan Wu, ${ }^{1}$ Abhinav Goyal, ${ }^{2}$ Yuntao Han, ${ }^{1}$ Wenlong Cui, ${ }^{1}$ Jianhui He, ${ }^{1}$ \\ Xia Xiao, ${ }^{1}$ Keying Zhao, ${ }^{1}$ Feng Jiao, ${ }^{1}$ Ying Song ${ }^{1}$
}

${ }^{1}$ School of Public Health, Kunming Medical University, Kunming, China

${ }^{2}$ Emory University, Atlanta, Georgia, USA

\section{Correspondence to} Dr Le Cai, School of Public Health, Kunming Medical University, 1168 Yu Hua Street Chun Rong Road, Cheng Gong New City, Kunming 650500, China; caile002@hotmail.com

Received 20 October 2012 Accepted 7 March 2013 Published Online First 15 April 2013

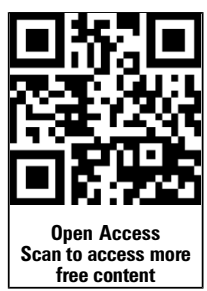

To cite: Cai L, Wu X, Goyal A, et al. Tob Control 2013;22:ii16-ii20.

\section{ABSTRACT}

Objectives To examine contextual and individual demographical predictors of smoking and exposure to second-hand smoke (SHS) in a tobacco-cultivating rural area of southwest China.

Methods A cross-sectional survey of 4070 consenting individuals aged 18 years or more was conducted in 2010. Information on demographical characteristics, tobacco smoking status and SHS exposure were obtained by a standard questionnaire. Multilevel logistic regression was used to model the variation in prevalence of smoking and SHS exposure.

Results In the study population, the prevalence rates of smoking and exposure to SHS were $63.5 \%$ and $74.7 \%$ for men, and $0.6 \%$ and $71.2 \%$ for women, respectively. Men were more likely to use tobacco than women: OR $8.27,95 \% \mathrm{Cl}$ (4.83 to 10.97). Age was inversely associated with the probability of tobacco use (OR 0.98 , $95 \% \mathrm{Cl} 0.97$ to 0.99 ), and exposure to SHS (OR 0.97, $95 \% \mathrm{Cl} 0.96$ to 0.99 ). Individual educational level was inversely associated with smoking, but showed no association with exposure to SHS. Adults who did not grow tobacco were less likely to consume tobacco (OR $0.75,95 \% \mathrm{Cl} 0.57$ to 0.99 ) and to be exposed to SHS (OR $0.76,95 \% \mathrm{Cl} 0.58$ to 0.99). Living in a highincome community was associated with a low rate of current smoking (OR $0.66,95 \% \mathrm{Cl} 0.57$ to 0.77$)$ and SHS exposure (OR $0.58,95 \% \mathrm{CI} 0.52$ to 0.65 ).

Conclusions Future interventions to reduce smoking and exposure to SHS in China should focus more on tobacco farmers, less-educated individuals and on poor rural communities.

\section{INTRODUCTION}

Tobacco control is a high-priority global public health challenge. China is the world's largest producer and consumer of tobacco products, and has the world's largest number of smokers. Ninety per cent of the Chinese smokers report smoking in public spaces, raising the total proportion of nonsmokers directly exposed to second-hand smoke (SHS) to more than 53.3\%. ${ }^{1}$ A total of 673000 deaths were attributable to smoking in China in $2005,{ }^{2}$ and trends in tobacco consumption remain alarming. ${ }^{3}$ The implementation of effective tobacco control policies should be of the utmost importance to public health in China.

Understanding the determinants of tobacco use can help guide the development of culturally appropriate tobacco control programmes. Research investigating individual risk factors for tobacco use has found that smoking is more prevalent among those who have a low level of education, limited income, history of divorce and farming as occupation. ${ }^{4-6}$ People with less education are more likely to be exposed to environmental tobacco. ${ }^{7}$ Western studies have examined the association between contextual socioeconomic status (SES) and tobacco use, and found that neighbourhood environment has an important influence on smoking. ${ }^{8-12}$ However, little is known about the association between contextual SES and exposure to SHS.

A Chinese study found that living in a high literacy area was associated with a low rate of smoking. ${ }^{13}$ However, information about tobaccocultivating rural areas of China is limited, where the prevalence of tobacco use is the highest. ${ }^{14}$ Previous Chinese attempts have largely focused on identifying individual-level risk factors for smoking, ${ }^{6} 15$ but the association between contextual SES and both smoking and exposure to SHS is still poorly understood in China. In order to bridge this knowledge gap, we used multilevel analysis to simultaneously examine the association between individual and contextual SES, and smoking and exposure to SHS, in a tobacco-cultivating rural adult population of southwest China in 2010.

\section{METHODS}

\section{Study area and population}

We conducted a community-based cross-sectional survey in Tonghai county of Yunnan province (one of the poorest provinces in southwest China). Tonghai county is an economically advantaged tobacco-cultivating rural area containing nine townships. In 2010, Tonghai county had a population of 279404 (137889 men and 141515 women); the ratio of men to women in the population aged 18 years or more was $0.802 .{ }^{16}$ The per capita gross domestic product was 15129 yuan (US\$2285), and tobacco was cultivated in eight townships, yielding $9796200 \mathrm{~kg}$ of tobacco.

To ensure the representativeness of the study sample, the groups selected for the study covered all nine township districts in Tonghai county. Three villages were chosen by the probability proportional to size method within each of the nine townships. A list of individuals aged 18 years or more was obtained from the village committee of the every selected village. Simple random sampling was then applied to select the sample subjects.

\section{Data collection and measurement}

Three village doctors from each selected village were employed as local facilitators and 30 medical 
students from Kunming Medical University were selected as interviewers for data collection. In order to ensure the accuracy and comparability of data collection, a workshop was conducted before the fieldwork to teach the medical students how to use the screening questionnaire and how to conduct an interview.

Each participant who gave informed consent was personally interviewed by one of the interviewers using a pre-tested and structured questionnaire. Information on demographical characteristics, smoking habits and SHS exposure was obtained.

\section{Ethical approval}

This study was approved by the ethics committee of Kunming Medical University before carrying out the research.

\section{Definitions and outcome variables}

Cigarette smokers were defined as persons who had smoked at least 100 cigarettes in their lifetime, and those persons who smoked any kind of tobacco product on a daily basis at the time of the survey were classified as current smokers. Exposure to SHS was defined in terms of persons who reported being exposed to another person's tobacco smoke at home or work for a minimum of $15 \mathrm{~min}$ at least 1 day/week. ${ }^{17}$ The adult illiteracy rate was defined as the percentage of the population aged 15 years and above who could neither read nor write with understanding a short simple statement on his/her everyday life. Ethnic minority was defined as any group of people having different culture, language or religion from that of the majority Han population.

\section{Independent variables}

Independent predictor variables included individual and township (contextual) characteristics. Individual characteristics were age, sex, ethnicity, yearly household income, education and tobacco-cultivating status. The township characteristics or contextual variables were the percentage with primary (grades 1-6) education or higher, percentage of ethnic minorities, average yearly income, population size, area of township and area of tobacco cultivation. Socioeconomic characteristics of townships for the year 2010 were obtained from the local statistics office.

\section{Statistical analysis}

Descriptive analyses and multilevel logistic regression modelling were used in this study. Multilevel logistic regression was applied to analyse the association between contextual socioeconomics variables and the dichotomous outcome measures of smoking and SHS exposure. The method of estimation was via a generalised linear model using penalised quasi-likelihood, with individual characteristics set at the first level and contextual characteristics at the second level. Individual and township characteristics were fixed effects. The association between contextual variables and smoking and SHS exposure were expressed in terms of ORs and their 95\% CI were computed. Age-adjusted prevalence rates of smoking and exposure to SHS were computed by indirectly standardising to the overall sample. All statistical significance decisions were based on two-tailed $\mathrm{p}$ values. Data analyses were done with R software V.2.9.2. ${ }^{18}$

\section{RESULTS}

A total of 4120 individuals aged 18 years or more were selected by the sampling process. Of these, 4070 participated, representing an overall response rate of $98.8 \%$.

Table 1 shows the participants' demographical characteristics. The participant population consisted of 1774 men and 2296 women. Among the study participants, $29.5 \%$ were from ethnic minorities, $20.2 \%$ were illiterate and $19.2 \%$ were engaged in tobacco cultivation. Male participants had higher level of education than female participants $(\mathrm{p}<0.05)$.

Table 2 presents prevalence of current smokers and exposure to SHS among the study participants. Men had remarkably high prevalence of current smokers than women $(\mathrm{p}<0.01)$.

Prevalence of current smokers and exposure to SHS decreased with age, peaking at $33.2 \%$ and $78.2 \%$ in the total population aged 35-44 years. The Han majority had higher prevalence of current smokers and exposure to SHS than ethnic minorities $(\mathrm{p}<0.05)$. Individuals who cultivated tobacco had higher prevalence of current smokers and exposure to SHS than non-tobacco-cultivating people $(\mathrm{p}<0.01)$.

Table 3 summarises the township contextual variables and displays the distribution of age-adjusted prevalence of current

Table 1 Demographic characteristics of the study population

\begin{tabular}{|c|c|c|c|}
\hline Characteristics & Men $(n=1774)$ & Women $(n=2296)$ & All $(n=4070)$ \\
\hline \multicolumn{4}{|l|}{ Age (\%) (years) } \\
\hline $18-34$ & $416(23.4)$ & $503(21.9)$ & 919 (22.6) \\
\hline $35-44$ & $392(22.1)$ & $469(20.4)$ & $861(21.2)$ \\
\hline $45-54$ & $271(15.3)$ & $401(17.5)$ & $672(16.5)$ \\
\hline $55-64$ & $313(17.6)$ & $458(19.9)$ & $771(18.9)$ \\
\hline$\geq 65$ & $382(21.5)$ & $465(20.3)$ & $847(20.8)$ \\
\hline \multicolumn{4}{|l|}{ Ethnicity (\%) } \\
\hline Han & $1291(72.8)$ & $1577(68.7)$ & $2868(70.5)$ \\
\hline Minorities & $483(27.2)$ & $719(31.3)$ & $1202(29.5)$ \\
\hline \multicolumn{4}{|l|}{ Level of education (\%) } \\
\hline Illiterate & $222\left(12.5^{* *}\right)$ & $602\left(26.2^{* *}\right)$ & $824(20.2)$ \\
\hline Primary (grades 1-6) & $714(40.2)$ & $886(38.6)$ & $1600(39.3)$ \\
\hline Middle (grades 7-9) or higher & $838(47.2)$ & $808(35.2)$ & $1646(40.4)$ \\
\hline Tobacco cultivation & $393\left(22.2^{*}\right)$ & $390\left(17.0^{*}\right)$ & $783(19.2)$ \\
\hline \multicolumn{4}{|c|}{ Approximate yearly household income (yuan) } \\
\hline Mean & 5508 & 4822 & 5136 \\
\hline Minimum-maximum & $100-250000$ & $100-180000$ & $100-25000$ \\
\hline
\end{tabular}


Table 2 Prevalence (\%) of current smoking and second-hand smoke exposure (SHS)

\begin{tabular}{|c|c|c|c|c|c|c|}
\hline \multirow[b]{2}{*}{ Variables } & \multicolumn{3}{|c|}{ Current smokers } & \multicolumn{3}{|l|}{ SHS } \\
\hline & Men, n (\%) & Women, n (\%) & All, n (\%) & Men, n (\%) & Women, n (\%) & All, $n(\%)$ \\
\hline \multicolumn{7}{|l|}{ Age (years) } \\
\hline $18-34$ & $268(64.4)$ & $0(0.0)$ & $268(29.2)$ & $309(74.3)$ & $364(72.4)$ & $673(73.2)$ \\
\hline $35-44$ & $284(72.4)$ & $2(0.4)$ & $286(33.2)$ & $313(79.8)$ & $360(76.8)$ & $673(78.2)$ \\
\hline $45-54$ & $184(67.9)$ & $3(0.7)$ & $187(27.8)$ & $202(74.5)$ & $311(77.6)$ & $513(76.3)$ \\
\hline $55-64$ & $189(60.4)$ & $2(0.4)$ & $191(24.8)$ & $227(72.5)$ & $321(70.1)$ & $548(71.1)$ \\
\hline$\geq 65$ & $202(52.9)$ & $6(1.3)$ & $208(24.6)$ & $274(71.7)$ & $278(59.8)$ & $552(65.2)$ \\
\hline \multicolumn{7}{|l|}{ Ethnicity } \\
\hline Han & $814(63.1)$ & $8(0.5)$ & $822\left(28.7^{\star}\right)$ & $1010(78.2)$ & 1098 (69.6) & $2108\left(73.5^{*}\right)$ \\
\hline Minorities & $313(64.8)$ & $5(0.7)$ & $318\left(26.5^{*}\right)$ & $377(78.1)$ & $474(65.9)$ & $851\left(70.8^{*}\right)$ \\
\hline \multicolumn{7}{|l|}{ Educational level } \\
\hline Illiterate & $197(88.7)$ & $10(1.7)$ & $207(25.1)$ & $161(72.5)$ & $446(74.1)$ & $607(73.7)$ \\
\hline Primary (grades 1-6) & $441(61.8)$ & $3(0.3)$ & $444(27.8)$ & $537(75.2)$ & $598(67.5)$ & $1135(70.9)$ \\
\hline Middle (grades 7-9) or higher & $489(58.4)$ & $0(0.0)$ & $489(29.7)$ & $627(74.8)$ & $590(73.0)$ & $1217(73.9)$ \\
\hline \multicolumn{7}{|c|}{ Approximate yearly household income } \\
\hline Low (<5136 yuan) & $674(62.2)$ & $9(0.7)$ & $683(27.8)$ & $804(74.2)$ & $990(72.3)$ & $1794(73.1)$ \\
\hline High ( $\geq 5136$ yuan) & $453(65.7)$ & $4(0.4)$ & $457(28.3)$ & $521(75.5)$ & $644(69.5)$ & $1165(72.1)$ \\
\hline \multicolumn{7}{|l|}{ Tobacco cultivation } \\
\hline Yes & $294(74.8)$ & $2(0.5)$ & $296\left(37.8^{* *}\right)$ & $348(88.8)$ & $340(72.5)$ & $688\left(87.9^{* *}\right)$ \\
\hline No & $833(60.3)$ & $11(0.6)$ & $844\left(25.7^{* *}\right)$ & $977(70.7)$ & $1294(67.9)$ & $2271(69.1 * *)$ \\
\hline All & $1127(63.5)$ & $13(0.6)$ & $1140(28.0)$ & $1325(74.7)$ & $1634(71.2)$ & $2959(72.7)$ \\
\hline
\end{tabular}

smokers and exposure to SHS among the nine townships. There were substantial variations in the percentage of minority ethnicities (varying from $3.1 \%$ to $97.1 \%$ ), population size (varying from 5665 to 65058 ), area of township (varying from 12.0 to 188.0) and area of tobacco cultivation (varying from 0.01 to 10.3). Again, men had markedly higher prevalence of current smoking than women.

Table 4 shows the results of multilevel analysis. Contextual and individual variables were associated with current smoking and exposure to SHS. Age was negatively associated with the probability of current smoking and exposure to SHS, and men were much more likely to consume tobacco than women. Individual educational level was negatively associated with current smoking, whereas it showed no association with exposure to SHS. Adults who grew tobacco were more likely to consume tobacco and to be exposed to SHS. Living in a highincome community was associated with a low rate of current smoking and exposure to SHS.

\section{DISCUSSION}

This study showed a high rate of smoking and exposure to SHS in a tobacco-cultivating rural area of southwest China. The prevalence rates of smoking in men and exposure to SHS in both sexes were greater than the prevalence rates observed in other parts of rural China and in other Asian and Western countries. ${ }^{5} 61920$ Furthermore, men reported remarkably higher rates of smoking than women in our study, this finding being consistent with other Chinese studies. ${ }^{2} 21$ Our findings emphasise an urgent need for tobacco control intervention strategies including the need to

Table 3 Distribution of socioeconomic status and age-adjusted prevalence rate (\%) of current smoking and second-hand smoke exposure (SHS) for the nine townships

\begin{tabular}{|c|c|c|c|c|c|}
\hline Variables & Minimum & $\mathbf{P}_{25}$ & $P_{50}$ & $\mathbf{P}_{75}$ & Maximum \\
\hline Percentage of primary (grades $1-6)$ education or higher (\%) & 78.7 & 78.7 & 84.4 & 88.1 & 94.0 \\
\hline Percentage of ethnic minorities (\%) & 3.1 & 8.1 & 14.8 & 63.0 & 97.1 \\
\hline Average yearly income (yuan) & 2854 & 4664 & 4762 & 5499 & 8976 \\
\hline Population size & 5665 & 8566 & 43549 & 50349 & 65058 \\
\hline Area of township $\left(\mathrm{km}^{2}\right)$ & 12.0 & 55.0 & 81.3 & 100.1 & 188.0 \\
\hline Area of tobacco cultivation $\left(\mathrm{km}^{2}\right)$ & 0.01 & 0.8 & 5.0 & 9.4 & 10.3 \\
\hline \multicolumn{6}{|l|}{ Current smokers } \\
\hline Men & 37.4 & 59.3 & 62.8 & 72.6 & 76.3 \\
\hline Women & 0.0 & 0.3 & 0.6 & 0.8 & 1.4 \\
\hline All & 12.6 & 21.8 & 28.4 & 31.7 & 36.7 \\
\hline \multicolumn{6}{|l|}{ SHS } \\
\hline Men & 33.5 & 54.3 & 69.0 & 77.2 & 78.6 \\
\hline Women & 40.9 & 53.9 & 70.3 & 76.1 & 82.2 \\
\hline All & 37.6 & 54.1 & 69.3 & 76.7 & 81.7 \\
\hline
\end{tabular}


Table 4 OR and 95\% Cl for multilevel logistic regression analysis of smoking and second-hand smoke exposure (SHS)

\begin{tabular}{|c|c|c|}
\hline Predictors & $\begin{array}{l}\text { Current smokers (reference: non-current smokers) } \\
\text { OR }(95 \% \mathrm{Cl})\end{array}$ & $\begin{array}{l}\text { Second-hand smoke exposure } \\
\text { (reference: non-SHS) } \\
\text { OR (95\% CI) }\end{array}$ \\
\hline \multicolumn{3}{|l|}{ Individual variables } \\
\hline Age & $0.98^{* * *}(0.97$ to 0.99$)$ & $0.98^{* * *}(0.97$ to 0.99$)$ \\
\hline Female sex (reference: male) & $0.002^{* * *}(0.001$ to 0.004$)$ & 0.90 (0.75 to 1.07$)$ \\
\hline \multicolumn{3}{|l|}{ Educational level (reference: illiterate) } \\
\hline Illiterate and primary (grades 1-6) & $0.94^{* *}(0.91$ to 0.98$)$ & 0.98 (0.95 to 1.00$)$ \\
\hline Middle (grades 7-9) or higher & $0.95^{* *}(0.92$ to 0.98$)$ & 0.98 (0.95 to 1.00$)$ \\
\hline Tobacco cultivation (reference: yes) & $0.76^{*}(0.57$ to 0.99$)$ & $0.76^{*}(0.58$ to 0.99$)$ \\
\hline \multicolumn{3}{|l|}{ Contextual variables } \\
\hline Average yearly income (per 1000 yuan increase) & $0.66^{*}(0.57$ to 0.77$)$ & $0.58^{*}(0.52$ to 0.65$)$ \\
\hline \multicolumn{3}{|l|}{ Measures of variation } \\
\hline Township-level variance (SE) & $0.42(0.078)$ & $0.31(0.063)$ \\
\hline Individual-level variance (SE) & $5.3(0.91)$ & $4.6(0.74)$ \\
\hline
\end{tabular}

implement comprehensive smoke-free laws to protect people from SHS in tobacco-cultivating rural areas of China.

In the study population, the prevalence of smoking and exposure to SHS decreased with increasing age, peaking at $33.2 \%$ (although this figure reflects a very low prevalence of smoking in women) and $78.2 \%$ in the total population aged 35-44 years. Age as an important predictor of smoking has been demonstrated in many previous studies. ${ }^{6} 1320$

In this study, individual educational level was inversely associated with the probability of current smoking and exposure to SHS, whereas contextual educational level showed no association with current smoking and exposure to SHS. The inverse relationship between individual educational level and both smoking and second-hand tobacco smoke exposure has also been found in other Chinese and Western studies. ${ }^{6} 721$ Our findings suggest that community-based tobacco control efforts should particularly target those with low levels of education about the harms of tobacco use.

Our study found that individuals who cultivated tobacco had higher prevalence rates of current smokers and exposure to SHS than non-tobacco-cultivating people. This is possibly due to tobacco farmers having less knowledge about the harms of tobacco use than non-tobacco-cultivating people. ${ }^{22}$ These results suggest that it is essential to strengthen tobacco farmers' awareness of tobacco hazards and to implement comprehensive smoke-free laws and legislations to protect them from SHS.

Low levels of income have been reported to be associated with high probability of consuming tobacco in developed and developing countries, ${ }^{52-24}$ and living in poor neighbourhoods is associated with an increased risk of daily smoking. ${ }^{25}$ Our study yielded no evidence supporting any association between individual income and smoking and exposure to SHS. Contextual income, however, was associated with a protective effect on smoking and exposure to SHS. Our result is different from that of these studies. ${ }^{25}$ The reason for this dichotomy is not clear. The inverse association of contextual income level with smoking and exposure to SHS in our study suggests that future interventions to reduce smoking and exposure to SHS in China should focus more on poor communities.

The following limitations of the study should be noted. First, self-reported smoking and exposure to SES were based on recall, and may therefore be subject to recall bias. Second, the lack of validation of smoking status with nicotine testing may underestimate the prevalence of smoking. Third, interactions were not tested to determine whether township SES effects on smoking and exposure to SHS varied by individual-level characteristic.

In conclusion, male smoking and exposure to SHS were very prevalent in the tobacco-cultivating rural community of southwest China, and future interventions to reduce smoking and exposure to SHS in China should focus more on tobacco farmers, less-educated individuals and on poor rural communities.

\section{What this paper adds}

This study simultaneously examined contextual and individual demographical predictors of smoking and second-hand smoke (SHS) among southwest China's tobacco-cultivating rural adult population. The findings indicated that adults who grew tobacco were more likely to consume tobacco and to be exposed to SHS. Living in a high-income community was associated with a low rate of current smoking. Our findings suggest that tobacco-cultivating status is an important consideration when developing tobacco control policies in rural China, and poor rural communities rather than rich ones should be targeted for future intervention programmes.

Acknowledgements This publication is based on the research funded by the Bill \& Melinda Gates Foundation. The findings and conclusions contained within are those of the authors and do not necessarily reflect positions or policies of the Bill \& Melinda Gates Foundation.

Contributors All authors have fulfilled all criteria for authorship, and read and approved the final manuscript.

Competing interests None.

Ethics approval This study was approved by the ethics committee of Kunming Medical University.

Provenance and peer review Not commissioned; externally peer reviewed.

Open Access This is an Open Access article distributed in accordance with the Creative Commons Attribution Non Commercial (CC BY-NC 3.0) license, which permits others to distribute, remix, adapt, build upon this work non-commercially, and license their derivative works on different terms, provided the original work is properly cited and the use is non-commercial. See: http://creativecommons.org/ licenses/by-nc/3.0/ 


\section{REFERENCES}

1 Li L, Chen QL. Patterns and burden of tobacco use in China. China Health Econ 2008;27:26-30 (in Chinese).

2 Gu D, Kelly TN, Wu X, et al. Mortality attributable to smoking in China. New Engl J Med 2009;360:150-9.

3 Liu BQ, Peto R, Chen ZM, et al. Emerging tobacco hazards in China: 1. Retrospective proportional mortality study of one million deaths. BMJ 1998;317:1411-22.

4 Siahpush M, Borland R, Taylor J, et al. The association of smoking with perception of income inequality, relative material well-being, and social capital. Soc Sci Med 2006;63:2801-12.

5 Ponniah S, Bloomfield A. Sociodemographic characteristics of New Zealand adult smokers, ex-smokers, and non-smokers: results from the 2006 Census. N Z Med J 2008; 121:34-42.

6 Yang $T$, Li F, Yang $X$, et al. Smoking patterns and sociodemographic factors associated with tobacco use among Chinese rural male residents: a descriptive analysis. BMC Public Health 2008;8:248.

7 Lee BE, Ha EH. Exposure to environmental tobacco smoke among South Korean adults: a cross-sectional study of the 2005 Korea National Health and Nutrition Examination Survey. Environ Health 2011;10:29.

8 Reijneveld SA. Neighborhood socioeconomic context and self reported health and smoking: a secondary analysis of data on seven cities. J Epidemiol Community Health 2002;56:935-42.

9 Gray L, Leyland AH. Is the "Glasgow effect" of cigarette smoking explained by socio-economic status? A multilevel analysis. BMC Public Health 2009;9:245.

10 Karvonen S, Sipilä $\mathrm{P}$, Martikainen $\mathrm{P}$, et al. Smoking in context-a multilevel approach to smoking among females in Helsinki. BMC Public Health 2008;8:134.

11 Galea S, Ahern J, Tracy M, et al. Neighborhood income and income distribution and the use of cigarettes, alcohol, and marijuana. Am J Prev Med 2007;32(6 Suppl): S195-202.

12 Chuang YC, Li YS, Wu YH, et al. A multilevel analysis of neighborhood and individual effects on individual smoking and drinking in Taiwan. BMC Public Health $2007 ; 7: 151$
13 Le C, Chongsuvivatwong V, Geater A, et al. Contextual and individual demographic determinants of alcohol consumption and smoking: a comparative study in southwestern China and southern Thailand. Southeast Asian J Trop Med Public Health 2009;40:370-9.

14 Cai L, Wu X, Goyal A, et al. Patterns and socioeconomic influences of tobacco exposure in tobacco cultivating rural areas of Yunnan Province, China. BMC Public Health 2012;12:842

15 Wu J, Liu Y, Rao K, et al. Education-related gender differences in health in rural China. Am J Public Health 2004;94:1713-16.

16 Yunnan Statistical Yearbook: 2010. Compiled by Yunnan Province Statistical Bureau. Beijing: China Statistics Press, 2011

17 Wang CP, Ma SJ, Xu XF, et al. The prevalence of household second-hand smoke exposure and its correlated factors in six counties of China. Tob Control 2009; 18:121-6.

$18 \mathrm{R}$ Development Core Team. R: A language and environment for statistical computing. Vienna, Austria: R Foundation for Statistical Computing, 2006

19 Katulanda P, Wickramasinghe K, Mahesh JG, et al. Prevalence and correlates of tobacco smoking in Sri Lanka. Asia Pac J Public Health 2011;23:861-9.

20 Xiao L, Yang Y, Li Q, et al. Population-based survey of secondhand smoke exposure in China. Biomed Environ Sci 2010;23:430-6.

21 Pomerleau J, Gilmore A, McKee $M$, et al. Determinants of smoking in eight countries of the former Soviet Union: results from the living conditions, lifestyles and health study. Addiction 2004;99:1577-85.

22 Wang $\mathrm{H}$. Knowledge and attitudes about tobacco planting among tobacco farmers in rural China. Adv Agric 2011;12:11-13 (in Chinese).

23 Neufeld KJ, Peters DH, Rani M, et al. Regular use of alcohol and tobacco in India and its association with age, gender, and poverty. Drug Alcohol Depend 2005:77:283-91.

24 Sun YH, Yu TS, Tong SL, et al. A cross-sectional study of health-related behaviors in rural eastern China. Biomed Environ Sci 2002;15:347-54.

25 Lemstra M, Mackenbach J, Neudorf C, et al. Daily smoking in Saskatoon: the independent effect of income and cultural status. Can J Public Health 2009:100:51-4. 